\title{
The impact of customer behaviour on the corporate competitiveness in the European environment
}

\author{
Marcela Kožená $^{1, *}$, Martin Mlázovský ${ }^{1}$ \\ ${ }^{1}$ University of Pardubice, Faculty of Economics and Administration, Institute of Economy and \\ Management, Studentská 84, 53210 Pardubice 2, Czech Republic
}

\begin{abstract}
Research background: Corporate competitiveness is closely connected with the competitive advantage. Contemporary developed European countries are characterised by being highly competitive. Thus, the competitive advantage is particularly bound by fulfilling the customer preferences and needs. However, there is a necessity to preserve and strengthen customer satisfaction and loyalty, in the long-run.

Purpose of the article: In the current globalised world, there is apparent high pressure on the sustainable development of the whole society. This trend was shifted from the mere legislation scope to the society-wide discussion. However, the previous researches prove that this trend is not reflected in the real purchasing behaviour in Czechia. Thus, the main aim of this article is to explore the role of customer behaviour in the corporate competitiveness paradigm concerning the current trend of corporate social responsibility.

Methods: Primary quantitative research is based on a questionnaire survey with Czech managers at the top and middle level. The data collection was conducted from April to June 2021 via personal interviewing. The questionnaire contained mainly close-ended questions. However, if it was relevant there were also used additional open-ended questions for a closer explanation of the question point.

Findings \& Value added: The results indicate that the Czech business mostly perceives as a key factor of corporate competitiveness innovation potential, not direct relationships with customers. However, this factor has a significant indirect connection with customer satisfaction. CSR has the lowest impact on corporate competitiveness according to the respondents. However, they predicate the upward trend of this factor, similar to the global environment.
\end{abstract}

Keywords: Corporate Competitiveness; Product Competitiveness; Customer Value; Customer Preferences; Customer Satisfaction

*Corresponding author: marcela.kozena@upce.cz 
JEL Classification: $M 31 ; M 10 ; D 91$

\section{Introduction}

Nowadays, several researches deal with the relationship between customer behaviour and corporate competitiveness. It is confirmed that a satisfied customer who remains loyal to the company and in addition recommends its products to other customers, is an important attribute of the current and future successful development of companies. The last decade has been very turbulent in terms of societal values and demands. There has been a significant shift in communication technologies, the world is no longer local, and it is becoming global. Companies have to deal with the very harsh conditions of multinational markets, where they encounter mainly oligopolistic competition; the system where is supply greatly exceeding demand. Thus, they need to acquire new markets - they need to globalise all their activities.

The majority of authors involved in defining the concept of business competitiveness (e.g., Porter, 1998) agrees that the basis of competitiveness is the gaining of a competitive advantage, which distinguishes their company from other competitors. The purpose is the bringing long-term profit and an advantageous competitive position.

In a modern approach, a competitive advantage can be gained and maintained mainly by the company's ability to satisfy customer needs (including pressure on sustainable development) in a completely new way in functional, emotional, social, epistemic or price value (Sweeney and Soutar, 2001). Central and Eastern Europe is still considerably focused on price sensitivity (Weber and Steiner, 2021). Besides the marketing communication, convenient distribution or product innovations, there is a significance of minimizing prices and rationalisation of using production capacity and resources.

Flak and Glod (2015) dealt with a broader research of corporate competitiveness. Their research contains a description of the integrated model of corporate competitiveness and its integral elements at micro- and macroeconomic level (Competitive potential, Strategy of competition, Competitive advantage, Competitive positioning, Platform of competition). The authors recommend to companies how to achieve and maintain a competitive advantage and thus increase their competitive potential in the long run.

Ran and Zhou (2019) studied the importance of establishing and maintaining a good relationship between companies and customers. It was found that the identification of customers with the company has a positive effect on reducing the number of their complaints and claims. Furthermore, these authors state the significant impact of customer innovation proposals on the improvement of provided services. Yen et al. (2020) also dealt with increasing customer satisfaction by including it in the process of development and innovation. In his research, he examines the relationship between innovation, customer engagement and value creation.

Jung et al. (2017) point out the importance of employees' behaviour who ensure communication with customers. The results of their research confirm the significant positive impact of this interpersonal communication on corporate competitiveness. The effects of corporate-customer interaction in retail are also discussed by Kim and Choi (2016). In their study, they analyse the sharing of experience with the product (company) by customers.

Jerath (2015) deals with the model for predicting multichannel customer behaviour in customer support. It is based on determining the frequency of customer inquiries and the choice of using the communication channel in the field of health insurance. It was found that the average information gain from a customers' call is twice as high as from a visit to a web portal.

The customer inconvenience, and following termination of purchasing behaviour, can also occur due to the disruptive behaviour of other customers (Gursoy, 2017). In his study, the author created seven categories of disruptive customer behaviour (e.g., parents with 
children, too noisy customers, etc.) and also suggested minimizing this behaviour to avoid unnecessary outflows of customers.

Nowadays, more and more customers prefer to buy products and services from companies that try to pollute the environment as little as possible, i.e., follow the concept of sustainable development. In a narrow context, sustainable development is perceived as the development of human society, which takes into account the ecological sustainability of intended and implemented activities. Businesses are required to follow this trend and also contribute to environmental protection. At the same time, many companies already see environmental protection not only as a factor that limits growth (protection technology costs) on the one hand but rather as a prerequisite for future growth in the current globalized market environment. In more general, the concept of sustainable development is not only dependent on the environment but also on the social and economic dimensions.

Holden et al. (2017) characterise the model of sustainable development in today's globalized world based on three moral requirements; to meet human needs, ensure social justice and respect environmental limits. This is somewhat at odds with the narrow definition of sustainable development; they rather confirm with the balance of social, environmental and economic goals in general. Holden et al. (2017) also state that sustainable development is a set of restrictions on human behaviour, including restrictions on economic activity. By identifying indicators and thresholds, it illustrates that different regions or groups of countries face different challenges. Other authors (Hull, 2008; Morse, 2008) state that the whole economy should review further global developments in that way, where sustainable development is integrated into all areas and aspects of human cultural evolution.

\section{Methods}

The aim of this paper is to define the impact of customer behaviour on corporate competitiveness in the context of sustainable development. A questionnaire survey with Czech managers on the top and middle level $(n=41)$ was conducted from April to June 2021 via personal interviewing. One of the main reasons for selecting the Czech businesses were their availability and willingness to complete the questionnaire. The research's topicality is evident from the long-term political and media attention to the global environment and pollution. In addition, there is highly discussed the current pandemic crisis and its impact on corporate competitiveness. For literature review were used primarily international sources, which were considered from the perspective of their relevance, significance, and topicality.

The question topics were created according to the defined focus. The specific meaning of questions was formulated on the basis of previous researches. The base of the questionnaire contained mandatory classification questions and 11 close-ended questions with multiple choice answer options or scaling questions. In addition, there were nine optional open-ended questions for a possible wider explanation of the discussed issue or placing it in the context of their own business activities.

The addressed managers were mostly employed by limited liability companies (categorized according to Act No. 90/2012, Coll.) of various sizes. Altogether, four corporations were classified as micro-sized, 11 as small businesses, 10 as medium-sized enterprises and 16 as large companies (evaluated according to Commission Recommendation 2003/361/EC) were surveyed. However, in the following results, there are assessed only two categories - SME and large enterprises due to higher reliability. Furthermore, there was surveyed a target market in the context of the direct customer (B2C, B2B) and finally related to the export behaviour. Altogether, 22 companies are operating on the B2B market and 19 corporates are focused on the B2C; 26 companies declared that they export their products and 15 did not have any customers abroad. 


\section{Results}

The results show that addressed managers mostly consider innovation potential as a key factor of corporate competitiveness on average (managers could choose only one key factor). Figure 1 shows the results in relation to the number of companies in the given category (corporate size, target market and exporting behaviour). There were also identified two significant differences. The first is in the employees' loyalty and qualification dimension the companies with B2B market focus selected that. The other divergent corporate category was caused by enterprises with a B2C market focus - they far more chose sustainability as a key factor of corporate competitiveness. The managers stated that they selected the innovation potential mainly due to product innovations, which are demanded by customers. The second crucial dimension was financial performance; the qualitative explanation given by managers is very obvious - lockdowns and connected lower turnovers (and same fixed costs) during coronavirus crises. Three others companies stated the classic view of enterprise - "the financial performance is the element for maintaining and improving others dimensions". Employee loyalty and qualification were in third place with a very small distance. The explanation is based on the lack of qualified employees in the Czechia; and also, this factor was more selected by service providers. Two companies chose their own criterion, in the first case it was product specialisation; in the other, it was product quality. Thus, both answers could be directly included in product innovations and indirectly into innovation potential, however, there were strictly kept respondents' answers.

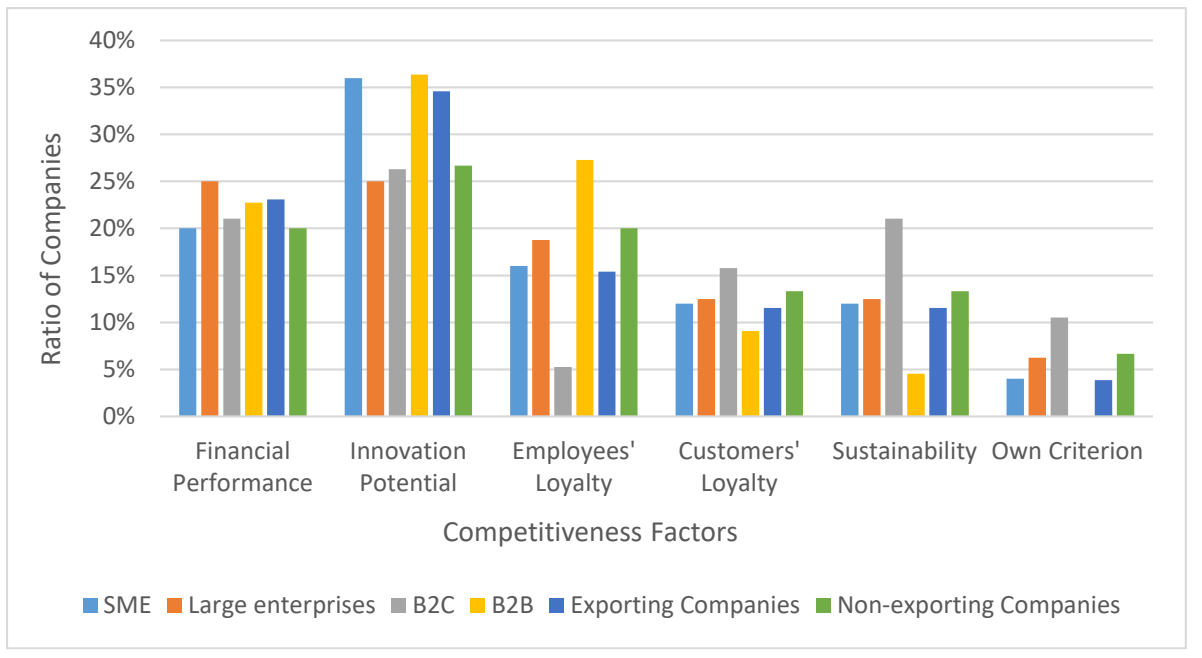

Figure 1. The key factor of corporate competitiveness

Source: own research

The following scaling question (four-point scale) on the same topic represents substantially more balanced answers. On average, the most significant factor is employees' loyalty and qualification. The only relevant exception was found at SME companies making business on the B2C market without exporting intention - their most favoured factor was Sustainability. Figure 2 shows a decomposition of competitiveness factors on the SME making business on the $\mathrm{B} 2 \mathrm{C}$ and $\mathrm{B} 2 \mathrm{~B}$ market, the third column represents large companies. The deeper decomposition was not shown due to the low count of B2C exporting SMEs, B2B non-exporting SMEs just like in the case of large companies. 


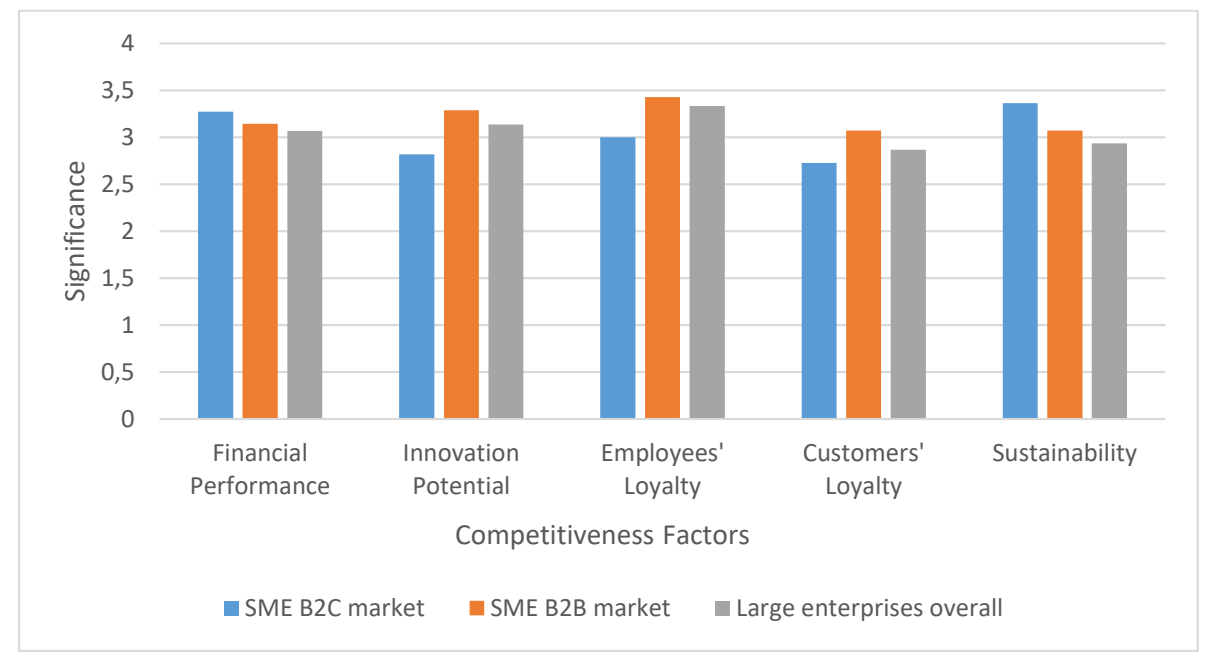

Figure 2. The significance of competitiveness factors

Source: own research

The first part of the main goal of this article is to explore the sustainability domain in the corporate competitiveness paradigm - this issue is represented by fig. 3 . There always was evaluated only one attribute. There is shown that the category of SME, B2C and nonexporting companies have a strong affiliation to the principles of sustainable development. The qualitative explanation is characterised by the statement "We prefer to maintain longterm stability over short-term success." This could also be perceived in the context of economic and social dimensions, not only in an environmental way. Moreover, seven managers predicate that environmental protection will be more and more significant factor of corporate competitiveness. However, there is a conflict with the cause of this rising - some managers stated that will be put pressure by the whole society (EU, national government, end-consumer); the others consider that the pressure will come only by EU or other transnational organizations

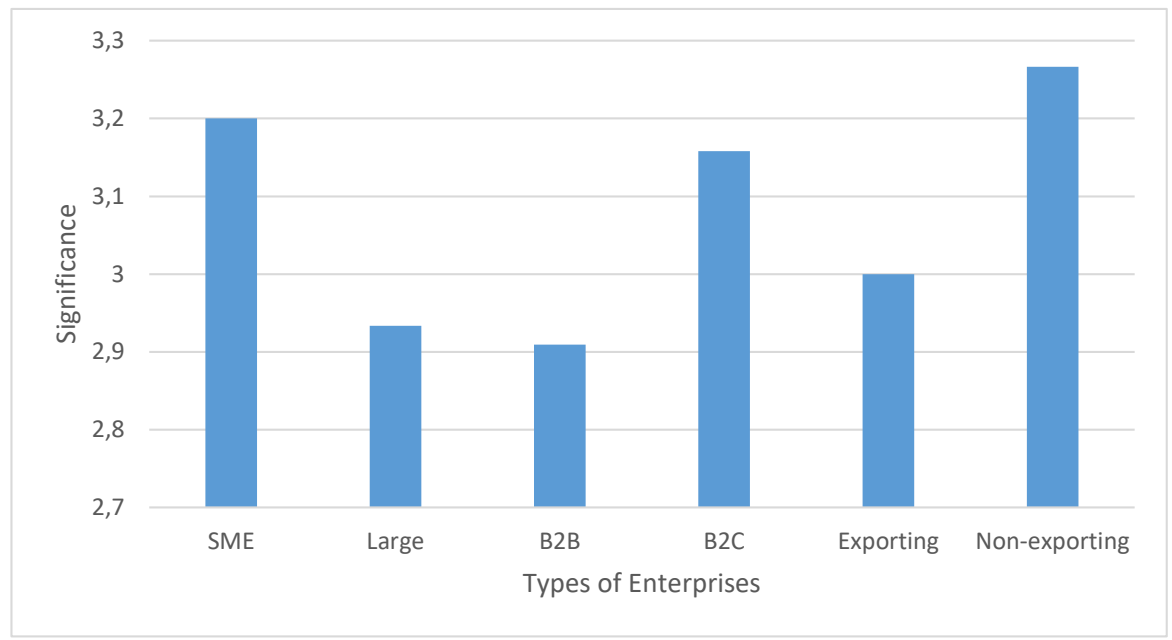

Figure 3. The significance of sustainability dimension for corporate competitiveness

Source: own research 
The other part of the main goal is to explore customer behaviour in the sustainability context. The following two questions were created on the product competitiveness perception of the addressed managers. There were defined multiple-choice answers in compliance with product competitiveness described in the literature review. The first question included answers for functional, emotional, social, epistemic or price value. The most often answer was product functions and attributes (20), the second was pricing (11), the third was brand and connection with specific consumer cohort (7) and finally, originality, innovativeness and curiosity (3). Emotional value or option for own criterion did not use anyone. Moreover, seven managers mentioned the second factor in order - in four cases it was a combination of functional and social value. Figure 4 shows more detailed data - the most divergent results are visible in the functional and social dimension (both preferred by exporting B2B corporates); there is also a strong difference in the pricing (preferred by non-exporting B2C small or mid-sized enterprises). Addressed managers concurred that the functional and social value is demanded in the whole Central Europe (specifically in Slovakia, Hungary, Austria, Poland and Germany). B2C enterprises added pricing as a core value in Central Europe. Western Europe (France, Italy, Great Britain) perceives as a key factor only functionality according to the addressed managers; however, all these companies are focused on B2B market, for $\mathrm{B} 2 \mathrm{C}$ market in this region are not any reliable data among respondents.

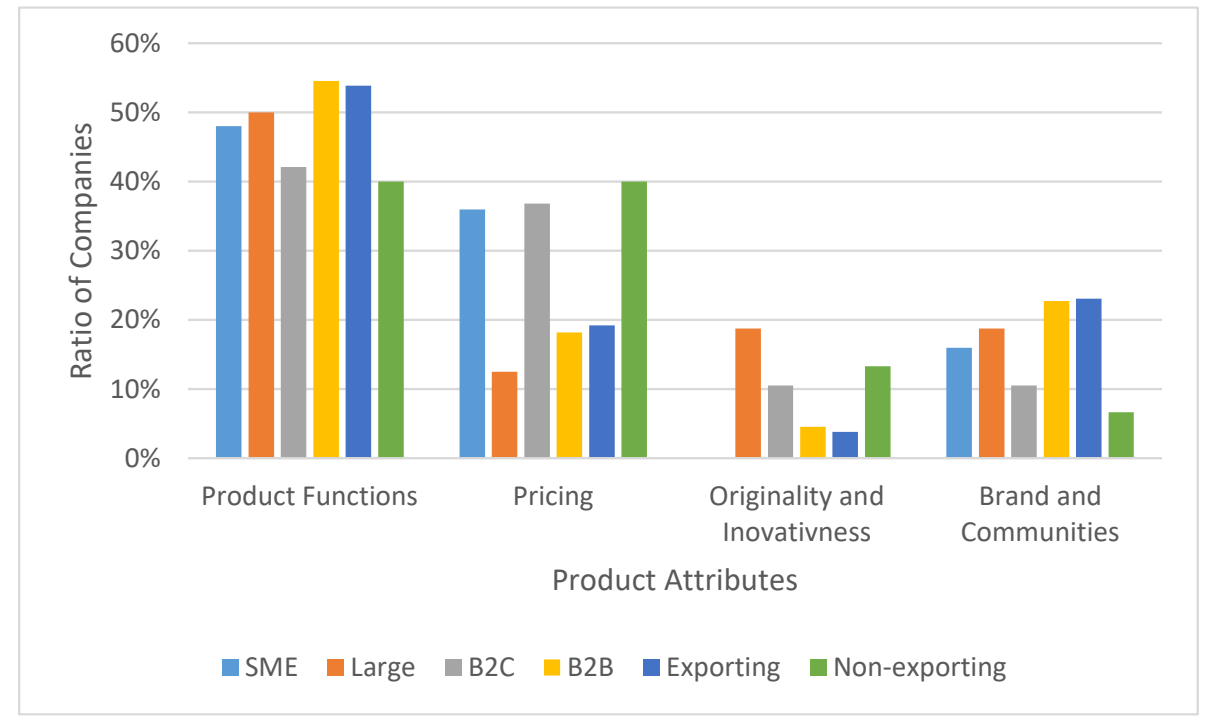

Figure 4. The significance of product competitiveness

Source: own research

The following question was focused on specific product attributes - there were 30 possible answers in total (managers could select more than one option). Figure 5 shows the selection of attributes related to sustainability. There is visible clear dominance of lifetime and durability favoured by non-exporting SMEs. On the other hand, the weakness of these companies is in the sphere of "easy repairability". For example, it means using screw joints instead of glued ones, which is also connected to the product functions. Both these attributes are connected to the functionality (see the previous figure); thus, this could be viewed as a contradiction. The results demonstrate a rather low attitude to the certification process; this is far more intensified since that was not only mentioned in the environmental context. There is also visible lack of concerns about consumption, it is mainly ignored by non-exporting corporates. A gradual transition from strict pricing to the combination of functionality and sustainability is already visible on the Czech B2C according to the addressed managers. 


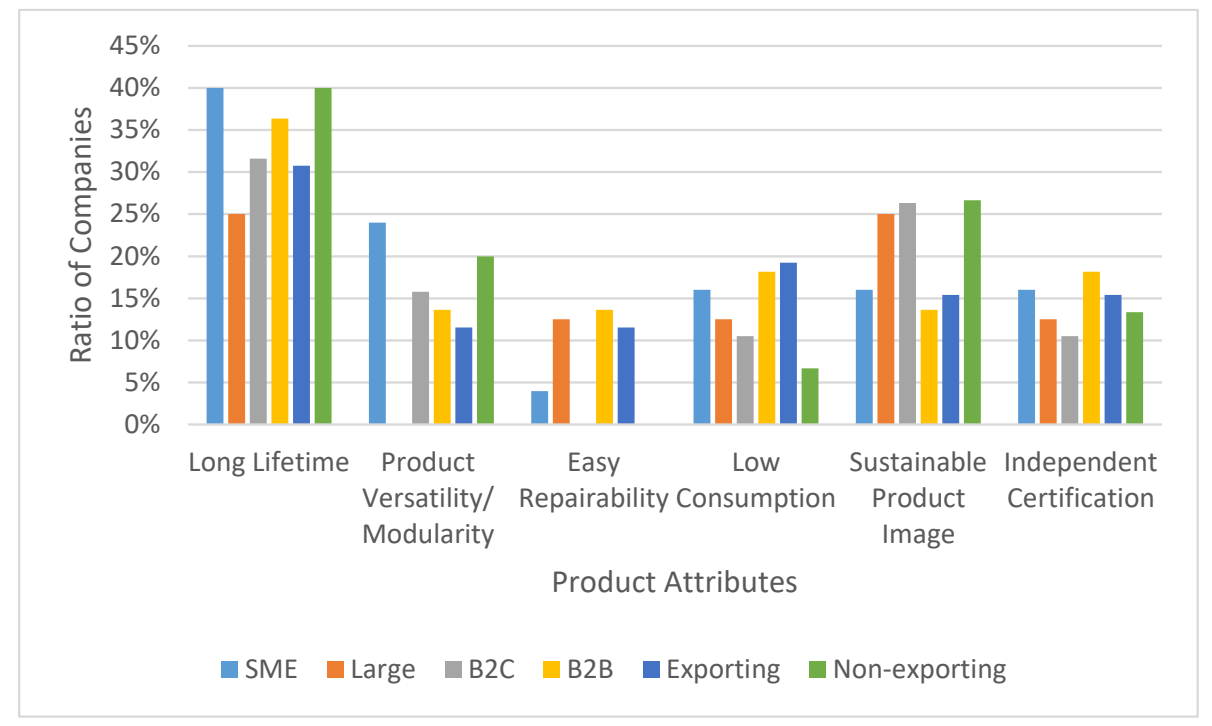

Figure 5. The significance of sustainable product attributes

Source: own research

\section{Discussion}

The classic approach to corporate competitiveness is based on financial performance, which is required for reaching other factors (Friedman, 1993). This is also confirmed by the research of product pricing and customer satisfaction nexus (Beerli-Palacio et al., 2020); connection of investment abilities and innovation potential (Ghisetti et al., 2017); or stimulating employees (Gächter and Thöni, 2010). Finally, the financial performance also supports corporate sustainability behaviour (Rodriguez-Fernandez, 2016).

However, the financial dimension was in second place by the addressed managers and what is more, it was only caused by the coronavirus crisis. The managers mentioned as a key competitiveness factor innovation potential and they explain that as a demand of customer purchasing behaviour. This explanation could be viewed as a contrast to the fact the customers' loyalty was the least chose option as a key factor. However, this contradiction is explained by the connected perception of those two domains and by corporate culture, which prefers internal focus over external (Übius, Alas, 2009). This is also a reason why Czech corporates mentioned a significant lack of qualified employees. On the other hand, there is a necessity to point out the unemployment rate - in Central and Eastern Europe (with exception of Austria) it is on the lowest level since 2011 (Eurostat, 2021).

On the global level, there is a necessity to manage sustainability in the whole supply chain. However, addressed respondents did not mention any activities for setting, supporting, managing or evaluating of sustainability their suppliers. Koberg and Longoni (2019) also surveyed that sustainable supply chain management is still elusive. A collaboration and strategy co-creation by suppliers, customers and other stakeholders is the key precondition for global sustainable development (Aguinis and Glavas, 2019; Freudenreich et al., 2020). Kusi-Sarpong et al. (2019) confirm high significance innovation potential and green product demand in the context of sustainable development.

Although, the addressed companies positive attitude to sustainability (particularly local B2B SME), there is visible a lack of process formalization, transparency and evaluation. However, these issues are not underestimated only in Czechia, but also on the global level 
(Goncalves and Silva, 2021). Furthermore, the addressed companies mostly often promote their sustainable product in the context of functional customer value (particularly long lifetime and durability). However, in Western Europe or the US is more common to embrace all customer value described in the literature review into the product mix (Ottman, 2011).

\section{Conclusion}

This research was focused on corporate competitiveness particularly in the context of customer behaviour and sustainable development. Although, customer satisfaction nor application of sustainability are not directly key factors of corporate competitiveness, thus there is a significant indirect connection. Addressed companies stated that innovation potential is important for going concern principle due to raising of stakeholders' pressure on the inclusion of CSR into common business activities. Furthermore, the innovation potential is also important to satisfy consumer needs - even though, these needs are mainly connected to the functional customer value. Thus, Czech (and mostly all Central European) consumers are focused on the saving attributes more than the environmental or social attitude.

Although, B2C companies have the most positive attitude to sustainability, that they mentioned the Czech consumer is still very dependent on pricing. In more detail, there is possible to conclude that this thinking particularly has non-exporting B2B small and midsized companies. Oppositely, there is surprising that energy or fuel consumption had a rather low evaluation. Even more, the easy reparability had the lowest appraisal at all - this also combined the functional and price value. According to communication from the European Commission (COM(2020) 98 final), there is a suggestion to establish a "right to repair" which also deals with environmental footprints in general.

Highly significant for small economies, like Czechia, is the global context. Altogether, 63\% of addressed companies are exporting and $77 \%$ of them stated direct export. The majority operates in Europe; there is an agreement that particularly Western Europe differs from the Czech market - they are already less dependent on the pricing. Asia is commonly perceived as a market without any sustainable intention. However, one addressed automotive company which expands to China and India states that this region is rapidly raising environmental protection, especially in the emission legislation. To the conclusion, there is possible to identify two trends - the first is a redirection of transition economies from price value to functional and partly social value, the other trend is redirection to the sustainability in developing countries.

\section{Acknowledgements}

This paper was supported by the Student Grant Competition (grant no. 12) of University of Pardubice in 2021.

\section{References}

1. Aguinis, H., \& Glavas, A. (2019). On Corporate Social Responsibility, Sensemaking, and the Search for Meaningfulness Through Work. Journal of Management, 45(3), 1057-1086.

2. Beerli-Palacio, A., Martín-Santana, J. D., \& Román-Montoya, C. (2020). Complementary services at hotels in accordance with their pricing strategy and the price sensitivity of tourists. International Journal of Hospitality Management, 87, Art. No. 102458. 
3. Eurostat. (2021, July 14). Unemployment by sex and age - annual data. Europa. https://ec.europa.eu/eurostat/databrowser/view/une_rt_a/default/table?lang=en

4. Flak, O., \& Glod, G. (2016). Features of polish companies. Results of the company competitiveness barometr 2014. Oeconomica Copernicana, 6(3), 117-135.

5. Freudenreich, B., Luedeke-Freund, F., \& Schaltegger, S. (2020). A Stakeholder Theory Perspective on Business Models: Value Creation for Sustainability. Journal of Business Ethics, 166(1), 3-18.

6. Friedman, M. (1993). Kapitalismus a svoboda. H\&H.

7. Gächter, S., \& Thöni, C. (2010). Social comparison and performance: Experimental evidence on the fair wage-effort hypothesis. Journal of Economic Behavior and Organization, 76(3), 531-543.

8. Ghisetti, C., Mancinelli, S., Mazzanti, M., \& Zoli, M. (2017). Financial barriers and environmental innovations: evidence from EU manufacturing firms. Climate Policy, 17(SI), S131-S147.

9. Goncalves, A., \& Silva, C. (2021). Looking for Sustainability Scoring in Apparel: A Review on Environmental Footprint, Social Impacts and Transparency. Energies, 14(11), Art. Noi. 3032.

10. Gursoy, D. (2017). Developing a typology of disruptive customer behaviors Influence of customer misbehavior on service experience of by-standing customers. International journal of contemporary hospitality management, 19(9), 2341-2360.

11. Holden, E., Linnerud, K., \& Banister, D. (2017). The imperatives of sustainable development. Sustainable development, 25(3), 213-226.

12. Hull, Z. (2008). Sustainable development: Premises, undestanding and prospects. Sustainable development, 16(2), 73-80.

13. Jerath, K., Kumar, A., \& Netessine, S. (2015). An information stock model of customer behavior in multichannel customer support services. Manfacturing \& Service Operations Management, 17(3), 368-383.

14. Jung, J. H., Brown, T. J., \& Zablah, A. R. (2017). The effect of customer-initiated justice on customer-oriented behaviors. Journal of business research, 71, 38-46.

15. Kim, H. S., \& Choi, B. (2016). The effects of three customer-to-custumer interaction quality types on customer experience quality and citizenship behavior in mass service settings. Journal of services marketing, 30(4), 384-397.

16. Koberg, E., \& Longoni, A. (2019). A systematic review of sustainable supply chain management in global supply chains. Journal of Cleaner Production, 207, 1084-1098.

17. Kusi-Sarpong, S., Gupta, H., \& Sarkis, J. (2019). A supply chain sustainability innovation framework and evaluation methodology. International Journal of Production Research, 57(7), 1990-2008.

18. Morse, S. (2008). Post-sustainable development. Sustainable development, 16(5) 341352.

19. Ottman, J. (2011). The New Rules of Green Marketing: Strategies, Tools, and Inspiration for Sustainable Branding. Greenleaf Publishing.

20. Porter, M. E. (1998). The competitive advantage of nations. New York: Free Press.

21. Ran, Y., \& Zhou, H. (2019) How does customer-company identification enhance customer voice behavior? A moderated mediation model. Sustainability, 11(16), Art. No. 4311. 
22. Rodriguez-Fernandez, M. (2016). Social responsibility and financial performance: The role of good corporate governance. Business Research Quarterly, 19(2) 137-151.

23. Sweeney, J. C., \& Soutar, G. N. (2001). Consumer perceived Value: The development of a multiple item scale. Journal of Retailing, 77(2), 203-220.

24. Weber, A., \& Steiner, W. J. (2021). Modeling price response from retail sales: An empirical comparison of models with different representations of heterogeneity. European Journal f Operational Research, 294(3), 843-859.

25. Yen, C. H., Teng, H. Y., \& Tzeng, J. C. (2020). Innovativeness and customer value cocreation behaviors: Mediating role of customer engagement. International journal of hospitality management, 88, Art. No. 102514. 